\title{
Experience with Silastic prostheses in the rheumatoid hand
}

\author{
A 5-year follow-up
}

\author{
A. G. L. KAY, J. V. JEFFS, AND J. T. SCOTT \\ From the Kennedy Institute of Rheumatology, London
}

SUMmARY Nine patients with rheumatoid arthritis, who had Silastic prostheses (Swanson's) introduced into 34 metacarpophalangeal joints, were reviewed 5 years after surgery. The most important long-term advantage conferred by the introduction of prostheses was pain relief; functional benefit was marginal. The majority of prostheses eventually fractured but this did not necessarily lead to a functional deterioration. Impairment of function was usually the result of loss of flexion at the metacarpophalangeal joints, but it was sometimes due to excessive instability after fracture of the prostheses. It is suggested that Silastic joint replacement may be a worthwhile procedure in rheumatoid patients with moderate destruction or deformity of the metacarpophalangeal joints when pain is a predominant feature. Significant functional improvement can be anticipated only when secondary to pain relief.

We have already reported preliminary experiences with Silastic prostheses for replacement of destroyed metacarpophalangeal joints (MCP) in rheumatoid arthritis (Rhodes et al., 1972). The short-term results were, both objectively and subjectively, encouraging, but as the initial benefits of various forms of surgery to the rheumatoid hand are not always maintained it was, of course, necessary to extend the follow-up period. The surviving patients from the original series were reviewed 5 years after MCP joint replacement.

\section{Patients}

Of the 11 patients in the original study 2 had died: the causes' of death were unrelated to the operations. 9 ( 2 male, 7 female) patients had survived and attended for 5-year postoperative follow-up. All the patients fulfilled the ARA criteria for definite or classical rheumatoid arthritis (Ropes et al., 1959): 8 were seropositive for rheumatoid factor and of these, 2 had shown evidence of digital vasculitis with nailfold lesions before surgery. The mean age at operation of the survivors was 55 years (range 39-66

Accepted for publication September 23, 1977

Correspondence to Dr A. G. L. Kay, ARC Epidemiology Research Unit, Clinical Epidemiology Section, Guy's Hospital, St Thomas Street, London SE1 9RT years) and the mean duration of disease at the time of operation was 13 years (range 4-30 years). The operation was carried out on 34 joints in 11 hands.

\section{Method}

A detailed examination was made of the hands including grip strength, range of movement of wrists, MCP joints, and proximal interphalangeal (PIP) joints. The presence or absence of pain, tenderness, swelling, and deformity was noted in the operated hands. $X$-rays of the hands and wrists were carried out. The findings were compared with the preoperative and early postoperative observations. A limited comparison was made between the operated and nonoperated hands in the 7 patients who had undergone surgery to one hand only.

Methods of evaluation were similar to those of the preliminary study. The main changes were as follows. (1) Grip strength was quantitatively assessed, as previously, but not power grip. (2) Ranges of finger joint movement were measured using a protractor (but not by a linear measurement from finger tip to palmar crease). (3) The patients' assessment of the result was recorded by them on a postal questionnaire in addition to a personal interview. (4) Photographs were not routinely included in the assessment. 


\section{Results}

Patients were on the whole still pleased with the results of surgery (Table 1) and pain relief was maintained in all but 1 . Only 4 however thought that their hand activities had improved: 2 admitted to a functional loss. The previously noted unanimous enthusiasm for further prostheses to other affected joints was still a striking feature, except for 1 patient with generalised active hand involvement.

\section{OBJECTIVE FINDINGS (TABLE 2)}

There was no recurrence of synovial swelling. Pain on motion remained relieved in all but three joints. Volar subluxation had recurred in only three of the operated digits whereas lateral instability had recurred in one-third of them. Ulnar drift recurred to a state unchanged from that before surgery in two-thirds of the operated joints. The improvement of grip strength was maintained in over half of the operated hands.

In the operated digits, MCP flexion was reduced in over two-thirds of the joints compared with the preoperative findings. Little finger MCP flexion was forty degrees or less in five of the operated hands. The overall loss of range at the MCP joints was accentuated by the frequent finding of fixed flexion with or without recurrence of subluxation.
In contrast, at the interphalangeal joint flexion had increased in two-thirds of the operated digitsFixed flexion of the PIP joints was present in thirteen digits preoperatively; the degree of fixe $\vec{\phi}$ flexion increased in most of these digits and was present in a further six at 5-year follow-up The range of extension/flexion at the interphalangeas joints was, thus, brought volarwards in these fingers

Fracture of the prostheses, at first suspected because of recurrence of subluxation and/or insta-bility, was confirmed by $x$-ray in seventeen digits an $\mathbb{P}$ was probable in another eleven, i.e. in more than four-fifths of the operated joints. The commones site of fracture was at the base of the distal sterfif (Fig. 1). Erosion of the radial aspect of the cortex of the shaft of the metacarpals, particularly the index was also seen in several cases (Fig. 2). There wers no other complications relating to the operation. of

Seven patients had undergone surgery to one hand only. At the time of assessment 3 patients thought the operated hand was better, and 3 worse, than the contralateral hand. One patient with active disease had no preference. 3 of these 7 patients had no pain. on joint movement in either hand. Grip strengthe wrist movement, and MCP and PIP flexion tendeœP to be greater in the nonoperated hand, but unfof tunately no consistent preoperative measurements of nonoperated hands had been carried out, so that

Table 1 Assessment by $8^{*}$ patients of the result of the introduction of Silastic prostheses at the MCP joints, 5 years after surgery

\begin{tabular}{|c|c|c|c|c|c|c|c|c|}
\hline \multicolumn{3}{|c|}{ Hand activities } & \multicolumn{3}{|l|}{ Pain } & \multicolumn{3}{|c|}{ Desire for further prostheses } \\
\hline Improved & Unchanged & Worse & Relieved & No change & Worse & Yes & Not sure & No \\
\hline
\end{tabular}

*One of the 9 patients died before receiving the questionnaire.

Note: Findings previously reported shown in parentheses.

Table 2 MCP joint changes 5 years after replacement with Silastic prostheses-34 joints

\begin{tabular}{|c|c|c|c|c|c|}
\hline \multirow[t]{2}{*}{ Joint changes } & \multirow{2}{*}{$\begin{array}{l}\text { No. of affected joints } \\
\text { before operation }\end{array}$} & \multicolumn{4}{|l|}{ Follow-up } \\
\hline & & Completely relieved & Moderately improved & Unchanged & Worse \\
\hline $\begin{array}{l}\text { Synovial swelling } \\
\text { Pain on motion } \\
\text { Volar subluxation } \\
\text { Lateral instability } \\
\text { Ulnar deviation }\end{array}$ & $\begin{array}{l}27(39) \\
23(30) \\
28(44) \\
19(28) \\
31(46)\end{array}$ & $\begin{array}{r}27(30) \\
20(29) \\
20(32) \\
13(14) \\
8(26)\end{array}$ & $\begin{array}{l}0(0) \\
1(1) \\
5(7) \\
0(4) \\
5(0)\end{array}$ & $\begin{array}{c}0(9) \\
0(0) \\
3(5) \\
1(5) \\
18(14)\end{array}$ & $\begin{array}{l}0(0) \\
2(0) \\
0(0) \\
5(5) \\
0(6)\end{array}$ \\
\hline Ulnar deviation & No. of hands & Improved & Unchanged & Worse & \\
\hline $\begin{array}{l}\text { Grip strength } \\
\text { Wrist extension } \\
\text { Wrist flexion }\end{array}$ & $\begin{array}{l}11(15) \\
9 \\
9\end{array}$ & $\begin{array}{l}7(11) \\
3 \\
3\end{array}$ & $\begin{array}{l}1(1) \\
0 \\
2\end{array}$ & $\begin{array}{l}3(3) \\
6 \\
4\end{array}$ & \\
\hline Wrist flexion & No. of fingers & Improved & Unchanged & Worse & \\
\hline $\begin{array}{l}\text { MCP flexion } \\
\text { PIP flexion }\end{array}$ & $\begin{array}{l}34 \\
34\end{array}$ & $\begin{array}{r}7 \\
23\end{array}$ & $\begin{array}{l}1 \\
3\end{array}$ & $\underset{8}{25}(+1$ flail $)$ & \\
\hline \multicolumn{6}{|c|}{ Note: Findings previously reported shown in parentheses. } \\
\hline
\end{tabular}






Fig 1. Fracture of prostheses at the base of the distal stems.

comparison between the two hands pre- and postoperatively was not possible.

\section{OBSERVER'S ASSESSMENT OF FUNCTIONAL RESULT}

The objective findings, considered with the patient's opinion, suggest that 4 patients had benefitted overall, 3 were unchanged, and 2 were worse than before hand surgery (Table 3 ). The better functional results were found in patients whose wrists were stable with little or no radial deformity and whose MCP joints were not grossly deformed preoperatively.

Table 3 Observer's assessment of functional result 5 years after operation in 8 patients

\begin{tabular}{llll}
\hline Excellent & Improved & Unchanged & $\begin{array}{l}\text { Worse than } \\
\text { before operation }\end{array}$ \\
\hline $1(5)$ & $3(5)$ & $3(2)$ & $2(0)$ \\
\hline
\end{tabular}

Note: Findings previously reported shown in parentheses

\section{Discussion}

The reported results of introducing Silastic implants at the MCP joints in rheumatoid hands have on the whole been encouraging (Swanson, 1972; Allieu et al., 1974; Griffiths and Nicolle, 1975; Mannerfelt and Anderson, 1975) although the mean period of follow-up of these studies was shorter than our own. As Swanson (1976) suggests, the ideal arthroplasty should be pain-free, mobile, stable, and durable. In our series only the first aim appears to have been fulfilled. Loss of flexion, which has previously been described (Allieu et al., 1974; Mannerfelt and Anderson, 1975) occurred in the majority of replaced joints and when severe, particularly in the little finger, impaired power grip. Fractures of the prostheses have been described at rates varying from $1.9 \%$ (Swanson, 1972) to approximately $25 \%$ in an $x$-ray study which includes tomography (Hagert et al., 1975). The high fracture rate observed in our series may be related to the longer mean follow-up period. Paradoxically, about half of the fractures appeared to be beneficial in that they allowed adequate MCP flexion to be maintained but associated instability was evident in others and, not unexpectedly, impaired function. The siting of fractures and cortical erosions concurred with the experience of other observers (Hagert et al., 1975). The 2 patients with preoperative nailfold vasculitis both had a good operative result: it is not recorded whether or not they also had impairment of digital artery pulsation.

Although MCP joints submitted to implant surgery will have been damaged by the disease it may be wise to avoid this operation in severely disorganised joints; the one hand in the series with severe preoperative disorganisation has gone on to catastrophic deformity and dysfunction, according with the concept of Silastic prostheses functioning as inert space-fillers dependent on adequate and reasonably normal motor function over the implanted 'joint'.

It is surprising that even those patients with, objectively, less good results from implant surgery were willing to have further prostheses to affected joints. A possible explanation is that rheumatoid

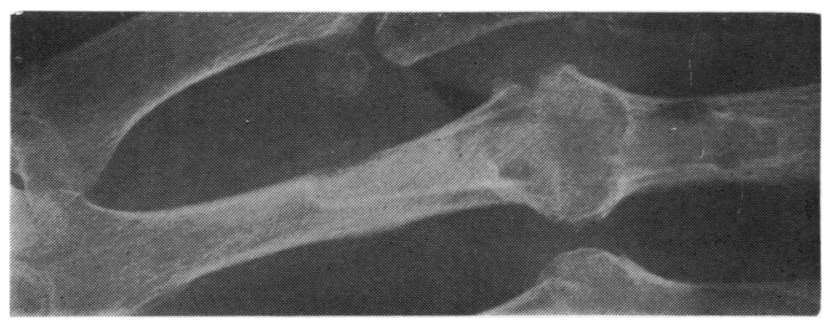

Fig. 2 Erosion of the radial cortex of the shaft of a metacarpal. 
patients derive psychological benefit from a period of extra care, such as is associated with a surgical procedure. The value of our findings would have been greater if the series of patients had been larger and if it had been possible to compare the results with those after other forms of MCP arthroplasty or soft tissue reconstructive surgery around the MCP joint.

\section{References}

Allieu, Y., Dimeglio, A., and Pech, J. (1974). Metacarpophalangeal arthroplasty using Swanson implants in cases of rheumatoid hands. Critical assessment of results. Annales de Chirurgie, 28, 873-882.

Griffiths, R. W., and Nicolle, F. V. (1975). Three years experience of metacarpophalangeal joint replacement in the rheumatoid hand. The Hand, 7, 275-283.
Hagert, C-G., Eiken, O., Ohlsson, N-M., Aschan, W., and Movin, A. (1975). Metacarpophalangeal joint implants Journal of Plastic and Reconstructive Surgery, 9, 147-157.

Mannerfelt, L., and Anderson, K. (1975). Silastic arthro plasty of the metacarpophalangeal joints in rheumatoif arthritis. Journal of Bone and Joint Surgery, 57A, 484-489.

Rhodes, K., Jeffs, J. V., and Scott, J. T. (1972). Experienc它: with Silastic prostheses in rheumatoid hands. Annals of the Rheumatic Diseases, 31, 103-108.

Ropes, M. W., Bennett, G. A., Cobb, S., Jacox, R., an Jessar, R. A. (1959). Diagnostic criteria for rheumatoid arthritis. 1958 revision. Annals of the Rheumatic Diseasesp 18, 49-53.

Swanson, A. B. (1972). Flexible implant arthroplasty fo $\overrightarrow{5}$ arthritic finger joints. Journal of Bone and Joint Surgerys 54A, 435-455.

Swanson. A. B. (1976). Flexible implant arthroplasty in the् hand. Clinics in Plastic Surgery, 3, 141-157. 